\title{
Significance of Dna Mismatch Repair Genes and Microsatellite Instability in Colorectal Carcinoma in Ibadan, Nigeria
}

\author{
BM Duduyemi ${ }^{1, *}$, EEU Akang ${ }^{2}$, PA Adegboyega ${ }^{3}$, JO Thomas $^{3}$ \\ ${ }^{1}$ Department of Anatomic Pathology, Ekiti State University, Ado-Ekiti, Nigeria \\ ${ }^{2}$ Department of Pathology, University College Hospital, Ibadan, Nigeria \\ ${ }^{3}$ Department of Pathology, Louisiana State University, Health Sciences Center, Shreveport, LA, USA \\ *Corresponding author: babsdudu@yahoo.com
}

Received August, 2013; Revised November 25, 2013; Accepted December 02, 2013

\begin{abstract}
Background: Though the incidence of colorectal carcinoma (CRC) is relatively uncommon in Nigeria, compared to the developed countries, recent studies indicate an increasing trend. Our patients often present at an earlier age, which has important implications for the pathogenesis in Nigeria. MLH1, MSH2, MSH6, PMS2 are the commonly mutated MMR genes in descending order of frequency, with PMS1 and MLH3 mutations being very rare. This study attempts to determine the significance of microsatellite instability (MSI) in colorectal carcinogenesis using immunohistochemistry (IHC) for detection of defects of DNA mismatch repair gene (MMR) amongst cases diagnosed at University College Hospital (UCH) Ibadan, Nigeria. Methodology: Suitable consecutive CRC cases identified from UCH, Ibadan, Pathology Department, 2006 files were stained with MMR IHC antibody panel (MLH1, MSH2, MSH6, PMS2). Stained sections were reviewed for nuclear reactivity and graded according to staining intensity (weak +, moderate ++, strong +++, very strong ++++). Result: IHC was performed on 26 cases. The age range is 22-74 years with 9 cases $<40$ years. One case with no reactivity with any of the antibody was considered unsuitable. Two cases with only PMS2 nuclear reactivity but no reaction with other antibodies were considered equivocal. Five cases had no nuclear reactivity with single antibody: MLH1 (2); MSH2 (3); and one case had no nuclear reactivity with MLH1 \& MSH2. These six cases included 3 cases aged 22, 27 and 32 years with tumors showing no nuclear reactivity for MSH2 and (MLH1 \& MSH2) respectively. Conclusion: Though the number cases tested are small, the identification of the loss of MMR gene protein (MLH1 and MSH2) by IHC, indicating MSI, in a significant number of the 26 cases tested (23\%), particularly young individuals, suggests that defects of DNA mismatch repair genes are important factors in colorectal carcinogenesis in Nigerians.
\end{abstract}

Keywords: CRC, microsatellite instability, MMR, IHC

Cite This Article: BM Duduyemi, EEU Akang, PA Adegboyega, and JO Thomas, "Significance of Dna Mismatch Repair Genes and Microsatellite Instability in Colorectal Carcinoma in Ibadan, Nigeria." American Journal of Medical and Biological Research 1, no. 4 (2013): 145-148. doi: 10.12691/ajmbr-1-4-7.

\section{Introduction}

Colorectal carcinoma (CRC) is relatively uncommon in Nigeria, compared to the developed countries. In 2008, colorectal cancer was the third commonest cancer in males and the second in females worldwide. However almost $60 \%$ of these cases occurred in developed countries and only $2 \%$ of new cases and $3 \%$ of deaths due to colorectal cancer occurred in Africa (Globocan 2008) [1]. Recent studies of CRC indicate an increasing trend, which has been attributed to the adoption of sedentary western lifestyle and diet, migration patterns and the improved availability of requisite specialized medical services $[2,3,4,5]$.

Patients with CRC in Nigeria and other developing countries often present at an earlier age than in developed countries [2,3], which has important implications for the molecular pathogenesis of CRC in our patients.

Hereditary non-polyposis colorectal cancer (HNPCC), the commonest cause of familial colorectal cancer occurs at an early age is associated with development of multiple colorectal or extra-colonic HNPCC-associated neoplasms as well as germ-line mutations of the mismatch repair (MMR) genes [6]. These MMR genes encode the proteins that correct random errors and mismatches that occur in the normal replication of DNA. MLH1 (chromosome 3p21), MSH2 (chromosome 2p22), MSH6 (chromosome 2p21), PMS2 (chromosome 7p22) are the commonly mutated MMR genes in descending order of frequency. Ninety per cent of mutations involve MSH2 and MLH1, while PMS1 and MLH3 mutations are very rare. The germ-line mutations in any MMR genes results in genomic instability involving most especially repetitive mono- or di-nucleotide microsatellite DNA sequences 
resulting in microsatellite in stability (MSI). In addition to HNPCC, $10-15 \%$ of sporadic colorectal cancers exhibit MSI [7].

There is a dearth of literature regarding the molecular pathogenesis of colorectal carcinoma in indigenous black African patients. A previous case report on HNPCC in Nigeria suggests that MMR genes may play an important role in the etiology of CRC in Africa [6].

This study attempts to determine the significance of microsatellite instability (MSI) in colorectal carcinogenesis using immunohistochemistry (IHC) for detection of defects of DNA mismatch repair gene (MMR) amongst cases diagnosed at University College Hospital (UCH) Ibadan, Nigeria.

\section{Materials and Methods}

Consecutive cases of histologically confirmed colorectal carcinoma (CRC) seen during one year were identified from a clinicopathologic study performed at the Department of Pathology, University College Hospital (UCH), Ibadan [2]. Data regarding demographic status were retrieved from the request forms; and classification done using the WHO (2000) histological classification of tumour of colon and rectum. Tumour staging was done using the American Joint Classification on Cancer (AJCC) [8]. The archival paraffin embedded tissue blocks of the tumor samples of these patients were retrieved. Cases in which the paraffin blocks could not be retrieved were excluded. Fresh hematoxylin and eosin stained slides were prepared from the paraffin blocks and histologically examined. Cases of anorectal squamous cell carcinoma, metastatic tumors, and malakoplakia were excluded from further study. Of the 32 cases originally collected, 26 cases of colorectal adenocarcinoma were identified and selected for immunohistochemical (IHC) study.

From formalin-fixed paraffin embedded tissue, sections of 3 micrometer thickness were cut, deparaffinized, and rehydrated. These sections were stained with an MMR IHC antibody panel (MLH1, MSH2, MSH6, PMS2).

Stained sections were reviewed for nuclear reactivity and graded according to staining intensity (weak +, moderate ++ , strong +++ ).

The data obtained was analyzed using SPSS 16 and EPI-Info. Continuous variables were compared using the Student $\mathrm{t}$ test, while discontinuous variables were compared using the $\chi^{2}$ test. The level of significance was set at $\mathrm{p} \leq 0.05$.

\section{Results}

The age range of the 26 cases studied with IHC is 22-74 years with nine cases (34.6\%) aged $<40$ years.

One case with no reactivity with any of the antibodies was considered unsuitable. Two cases with only PMS2 nuclear reactivity but no reactions with other antibodies were considered equivocal. Five cases had no nuclear reactivity with a single antibody; MLH1 in two cases and MSH2 in three cases. In one case there was no nuclear reactivity with both MLH1 and MSH2. Three of these six cases were aged 22, 27 and 32 years respectively.
Figure 1 and Figure 2 show the IHC staining reactivity patterns with the different antibodies.

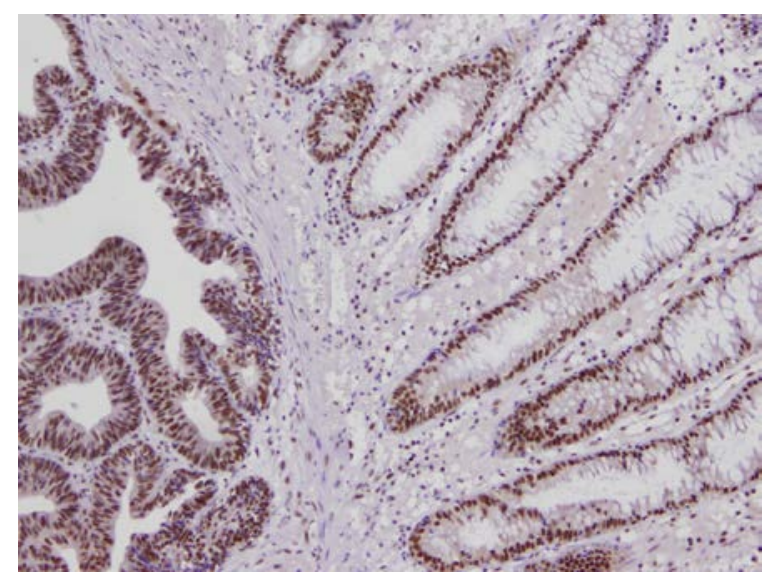

Figure 1. Strong nuclear reaction with PMS2 in tumor cells (left) and normal colonic crypts (right) as internal control
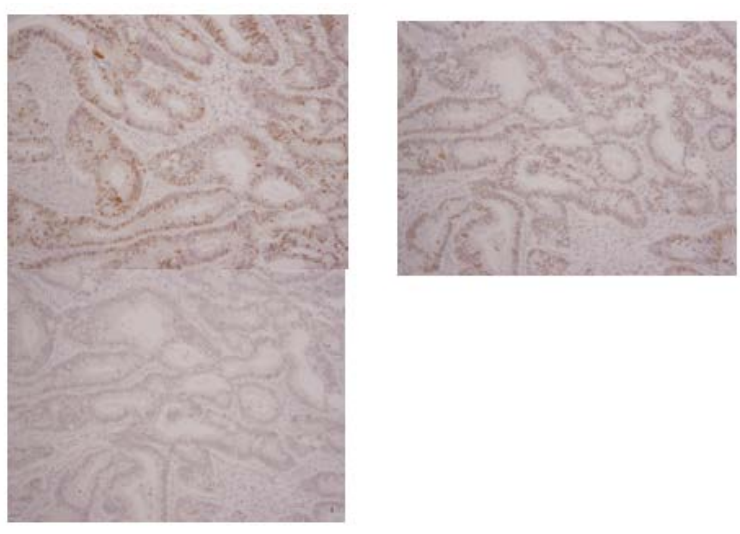

Figure 2. Moderate nuclear reactivity of tumor cells with MSH6 (Aupper left) weak nuclear staining with MSH2 (B- upper right) and no staining with MLH1 (C- lower left)

Eight (30.8\%) of the cases demonstrated loss of expression of MLH1. Seven (43.7\%) of the 16 colonic tumors were negative for MLH1, compared to only one $(10 \%)$ of the ten rectal tumors $(p=0.07)$. There was no correlation between loss of MLH1 expression and any of the other clinical or morphological parameters.

Nine (34.6\%) of the cases were negative for MSH2 (Table 1). While nine (56.2\%) of the colonic tumors were negative, none of the ten rectal tumors showed loss of MSH2 expression ( $p=0.003)$. In addition, while both of the two signet ring carcinomas were negative, only seven (29.2\%) of the 24 adenocarcinomas and mucinous carcinomas were negative $(\mathrm{p}=0.04)$. Both of the two T4 cases demonstrated lack of MSH2 expression, whereas seven $(29.2 \%)$ of the 24 T2 or T3 were negative $(p=0.04)$. In addition, whereas only six (27.3\%) of the $22 \mathrm{N0}$ cases were negative for MSH2, three (75\%) of the four N1 or N2 cases were negative $(\mathrm{p}=0.04)$. There were weak nonsignificant positive correlations between loss of MSH2 expression and both increasing grade and stage $(\mathrm{p}=0.1$ each). Table 2 summarizes the significance of the different parameters tested for MSH2.

Five (19.2\%) of the cases showed lack of MSH6 expression. Five (31.2\%) of the colonic tumors were negative, while none of the rectal tumors were negative ( $p$ $=0.05$ ). As shown in Table 2 , there was no correlation 
between MSH6 expression and any of the other clinical or morphological parameters.

Table 1. Results of immunohistochemical staining for selected DNA mismatch gene products in the 26 cases

\begin{tabular}{|c|c|c|c|c|c|}
\hline \multirow[b]{2}{*}{ Antibodies } & \multicolumn{4}{|c|}{ Positive } & \multirow[b]{2}{*}{ Negative } \\
\hline & Weak & Moderate & Strong & $\begin{array}{c}\text { Very } \\
\text { strong }\end{array}$ & \\
\hline $\begin{array}{c}\text { PMS2- C20 } \\
\text { clone }\end{array}$ & 5 & 5 & 13 & 2 & 1 \\
\hline $\begin{array}{l}\text { PMS2- H300 } \\
\text { clone }\end{array}$ & 12 & 7 & 0 & 0 & 7 \\
\hline MLH1 & 11 & 5 & 2 & 0 & 8 \\
\hline MSH2 & 10 & 5 & 2 & 0 & 9 \\
\hline MSH6 & 11 & 3 & 7 & 0 & 5 \\
\hline
\end{tabular}

Table 2. Comparison of MSH2 and MSH6 expression with clinical and morphological parameters

\begin{tabular}{|c|c|c|}
\hline $\begin{array}{c}\text { Clinical and morphological } \\
\text { parameters }\end{array}$ & MSH2 expression & $\begin{array}{c}\text { MSH6 } \\
\text { expression }\end{array}$ \\
\hline Age & Not significant & Not significant \\
\hline Sex & Not significant & Not significant \\
\hline Location (colonic vs. rectal) & $\begin{array}{c}\text { Significant (p }= \\
0.003)\end{array}$ & $\begin{array}{c}\text { Significant (p } \\
0.05)\end{array}$ \\
\hline $\begin{array}{c}\text { Histological type (signet ring } \\
\text { vs. others) }\end{array}$ & $\begin{array}{c}\text { Significant (p }= \\
0.04)\end{array}$ & Not significant \\
\hline $\begin{array}{c}\text { Tumor status (T2 and T3 vs. } \\
\text { T4) }\end{array}$ & $\begin{array}{c}\text { Significant (p }= \\
0.04)\end{array}$ & Not significant \\
\hline $\begin{array}{c}\text { Nodal status (N0 vs. N1 and } \\
\text { N2) }\end{array}$ & $\begin{array}{c}\text { Significant (p }= \\
0.04)\end{array}$ & Not significant \\
\hline Stage & Not significant & Not significant \\
\hline Grade & Not significant & Not significant \\
\hline
\end{tabular}

\section{Discussion}

In the present study, a minority of the tumors demonstrated loss of expression of the five microsatellite instability (MSI) markers tested. This suggests that the MSI pathway is only involved in a small subset of colorectal carcinomas among the cohort of patients that were tested [9]. Geiersbach et al [9] opine that $15 \%$ of colorectal cancers are characterized by genomic microsatellite instability, and of these, about 1 in 5 (2\%$4 \%$ overall) are due to Lynch syndrome, a dominantly inherited condition predisposing the patient to cancers of multiple organ systems, including the gastrointestinal tract. Identification of individuals with Lynch syndrome allows for increased surveillance of the affected individual and of potentially affected family members.

Over one-third of our cases demonstrated loss of MSH2 expression. Jung et al 2012 in their study of 120 patients, only 15 of them show microsatellite instability [10]. These cases were associated with younger age ( $<50$ years), family history of cancer, right sided colon cancer and mucinous variant [10]. Loss of MSH2 expression was more strongly associated with colonic than rectal tumors [10,11,12].

There was also a significant association between lack of MSH2 expression and signet ring carcinomas. Kaug et al in Malaysia studied 148 patients with CRC and found a significant association between abnormal MMR gene protein expression and proximal colon cancers, mucinous, signet ring and poorly differentiated morphology [12].

Advanced $\mathrm{T}$ and $\mathrm{N}$ status were found to be significantly associated with lack of MSH2 expression [12]. However, there was only weak non-significant positive correlation between loss of MSH2 expression and both increasing grade and stage.
Only $19.2 \%$ of the cases demonstrated loss of MSH6 expression. Loss of MSH expression was more strongly associated with colonic tumors than rectal tumors [12].

There was a weak non-significant association of colonic tumors with loss of MLH1 expression [13], similar to MSH2 and MSH6. Recent study by Martinez-Uruena et al. [14] showed that there is a relationship between the MLH1 -93 G>A polymorphism in the homozygous state and the risk of sporadic colorectal cancer and that this variant appears to be related with the cases with focal IHC activity more than with the complete absence of the MLH1 protein in the tumour tissue. The small number of cases in the present study might have contributed to this finding.

Lack of PMS2 expression was also not associated with any of the clinical or morphological parameters studied.

In summary the present study has demonstrated that loss of MSH2 and MSH6 plays a role in the molecular pathogenesis of a subset of colorectal carcinomas among indigenous Africans.

\section{Conclusion}

A significant number of our patient population with CRC at UCH, Ibadan, present at relatively younger age, compared to the developed countries, which has implication for the etiopathogenesis. The study also confirms the suitability of our paraffin tissue blocks for MSI analysis using 4-antibody IHC panel. Though the number cases tested are small, the identification of the loss of MMR gene protein (MLH1 and MSH2) by IHC, indicating MSI, in a significant number of the 26 cases tested (23\%), particularly young individuals [15], suggests that defects of DNA mismatch repair genes are important factors in colorectal carcinogenesis in Nigerians. Detailed prospective study is needed for further elucidation.

\section{References}

[1] Globocan 2008.

[2] Duduyemi BM, Oluwasola AO, Akang EEU, Thomas-Ogunniyi JO. A 16-year review of clinico-pathological pattern of colorectal carcinoma at University College Hospital, Ibadan. Nigerian Journal of Gastroenterology and Hepatology Vol.3 Nos. 1\&2 June \& Dec., 2011.

[3] Iliyasu Y, Ladipo JK, Akang EEU, Adebamowo CA, Ajao OG, Aghadiuno PU. A twenty-year review of malignant colorectal neoplasms at the University College Hospital Ibadan, Nigeria. Dis Colon Rectum 1996; 39:536-40.

[4] Akute OO. Colorectal carcinoma in Ibadan, Nigeria: a 20-year survey- 1971 to 1990. Hepatogastroenterology 2000; 47:709-13.

[5] Irabor D, Adedeji OA. Colorectal cancer in Nigeria: 40 years on. A review. European Journal of Cancer Care 2009; 18:110-5.

[6] Adebamowo CA, Adeyi O, Pyatt R, Prior TW, Chadwick RB, de la Chapelle A. Case report on hereditary non-polyposis colon cancer (HNPCC) in Nigeria. Afr J Med Med Sci 2000; 29:71-3.

[7] Rosai J (Ed): Rosai and Ackerman's Surgical Pathology. 9th edition. Elsevier, St Louis, Missouri, 2004: pp. 799-818.

[8] Hamilton SR, Aaltonen LA (Eds.): WHO classification of tumors: Pathology and Genetics of Tumors of the Digestive System. IARC Press, Lyon 2000; 103-19.

[9] Katherine B. Geiersbach, Wade S. Samowitz. Microsatellite Instability and Colorectal Cancer. Archives of Pathology \& Laboratory Medicine: October 2011, Vol. 135, No. 10, pp. 12691277. 
[10] Jung SB, Lee HI, Oh HK, Shin IH, Jeon CH. Clinico-pathologic Parameters for Prediction of Microsatellite Instability in Colorectal Cancer. Cancer Res Treat. 2012 Sep; 44(3):179-186.

[11] Vasen HF, Stormorken A, Menko FH, Nagengast FM, Kleibeuker JH, Griffioen G, Taal BG, Moller P, Wijnen JT. MSH2 mutation carriers are at higher risk of cancer than MLH1 mutation carriers: a study of hereditary nonpolyposis colorectal cancer families. J Clin Oncol. 2001 Oct 15; 19(20):4074-80.

[12] Kaur G, Masoud A, Raihan N, Radzi M, Khamizar W, Kam LS Mismatch repair genes expression defects \& association with clinicopathological characteristics in colorectal carcinoma. Indian J Med Res. 2011 Aug; 134:186-92.

[13] Abdul Murad NA, Othman Z, Khalid M, Abdul Razak Z, Hussain R, Nadesan S, Sagap I, Mohamed Rose I, Wan Ngah WZ, Jamal R.
Missense mutations in MLH1, MSH2, KRAS, and APC genes in colorectal cancer patients in Malaysia. Dig Dis Sci. 2012 Nov; 57(11):2863-72.

[14] Martínez-Urueña N, Alvarez LM, Pérez-Cabornero L, Sanz MI, Aras EL, Hernández JJ, Pino CM, Sarmiento RG, Domínguez MD. Incidence of -93 MLH1 promoter polymorphism in familial and sporadic colorectal cancer. Colorectal Dis. 2013 Feb 1. doi: 10.1111/codi.12112. [Epub ahead of print].

[15] Tanskanen T, Gylfe AE, Katainen R, Taipale M, RenkonenSinisalo L, Mecklin JP, Järvinen H, Tuupanen S, Kilpivaara O, Vahteristo P, Aaltonen LA. Exome sequencing in diagnostic evaluation of colorectal cancer predisposition in young patients. Scand J Gastroenterol. 2013 Apr 2. [Epub ahead of print]. 